\title{
MICROLEAKAGE OF CAVITY CLASS V RESTORED BY GLASS IONOMER RESTORATIONS IN PRIMARY MOLARS CONDITIONED BY Er,Cr:YSGG LASER VERSUS CONVENTIONAL METHOD (AN IN VITRO STUDY)
}

\author{
Ayman Abdel Hamid Sabah*
}

\begin{abstract}
Introduction: In the field of pediatric dentistry the use of Er,Cr:YSGG laser in cavity preparation in deciduous molars has many advantages as fast procedures and patient comfort.The purpose of the present study is to compare between the effect of Er,Cr:YSGG laser and conventional conditioning on the microleakage in cavity class $\mathrm{V}$ restored by glass ionomer (GI) and resin modified glass ionomer (RMGI) in deciduous molars.
\end{abstract}

Materials and methods: A standard class V cavity were prepared at the buccal or lingual surface of forty-eight freshly extracted caries-free human deciduous molars which were divided into 2 groups according to the mode of conditioning: group 1: by using Er,Cr:YSGG laser; group 2: by using conventional conditioning. The samples were subjected to thermocycling and dying step.

Results: No statistically significant difference between median microleakage scores of the two conditioning methods with RMGI or GI, while RMGI showed statistically significantly lower median microleakage scores than GI.

Conclusion: Er,Cr:YSGG laser have adverse effect on the microleakge of cavities restored by RMGI and GI. RMGI showed statistically significantly lower median microleakage scores than GI. Application of the Er:YAG laser, beneath the RMGIs and GI may be an alternative to acid etching

KEY WORDS: Microleakage, Er,Cr:YSGG laser, Glass ionomer, Resin Modified Glass ionomer.

\section{INTRODUCTION}

Alternative techniques for cutting and finishing of dental tissues during cavity preparation have been suggested for preservation of tooth structure and taking the advantages of new bonding systems ${ }^{1}$. New devices and materials, which put in consideration quick procedures and patient comfort specially the pediatric patient ${ }^{2,3}$. For seeking a more comfortable, gentle, and conservative excavation of caries lead to developing recent techniques in order to provide less vibration, pain, minimal thermal changes, and infected dentine removal only ${ }^{4}$.

\footnotetext{
* Pediatric Dentistry and Orthodontics, Faculty of Dentistry, MIU, Cairo
} 
The Federal Drug Administration (FDA), in 1997 give the approval to use the Er: YAG laser in hard tissues, and after two years later, also approved to be used in Pediatric Dentistry. The Er,Cr:YSGG laser was also approved later for cavity preparation in hard tissue, which causes less trauma and therefore aid in behavior management of child patient ${ }^{3,5-7}$. The Er:YAG $(2.94 \mu \mathrm{m})$ and Er,Cr:YSGG $(2.78 \mu \mathrm{m})$ lasers have several merits, which includes minimum noise, vibration and minimal or no need for local anesthesia administration than the conventional high-speed handpiece during cavity preparation, because their wavelength are absorbed well by the hydroxyapatite, and also coincide with the main absorption band of water ${ }^{8-15}$.

Several researches for many years, found that laser was applicable for cavity preparation, tooth structure preservation, and caries prevention as it is potentially used to increase acid resistance and effectively reduce micororganisms ${ }^{16,17}$. When using laser for cavity preparation, the quality of margins of the restoration should be high to effectively ensure marginal seal which is important for longevity of the restorative material and hence reducing the possible gaps between the tooth-restoration interface ${ }^{12,18-22}$ leading to movement of fluid and bacteria resulting in hypersensitivity, pulpal irritation, patient discomfort, and recurrent caries ${ }^{23}$.

Many adhesives systems and composite resin restorations have been used to enhance the bonding of composite resin restorations. In the field pediatric dentistry, GI cements are used as an another alternative to composite resin materials due to their adhesion ability to tooth structure, biocompatibility, low polymerization shrinkage, fluoride release, minimal microleakage, recurrent caries reduction, and acceptable esthetics ${ }^{24-26}$, where RMGI cements was introduced as a further development of the conventional GI, to improve its handling and working characteristics $^{27}$.

Several researches has been done on cavity preparation by Er:YAG laser in relation to microleakage and adhesion in both permanent and primary teeth, but the studies concerning the laser parameters and quality of cavities prepared with Er:YAG and Er,Cr:YSGG lasers and restored with different GI cements in primary teeth are sparse. So, the aim of this study was to assess the conditioning effect of Er,Cr:YSGG laser versus conventional conditioning on marginal microleakage in class $\mathrm{V}$ cavities prepared by Er,Cr:YSGG and restored by RMGI.

\section{MATERIALS AND METHODS:}

\section{Sample size calculation}

This power analysis is for a $2 \times 2$ fixed effects analysis of variance; the first factor (Material) includes 2 levels and the second factor(Conditioning) includes 2 levels. Based upon the results of Luong $\mathrm{E}$ and Shayegan A (2018) ${ }^{6}$ the effect sizes for the two factors were found to be ( 0.2 and 0.55 , respectively), using alpha $(\alpha)$ level of $(5 \%)$ and Beta $(\beta)$ level of $(20 \%)$ i.e. power $=80 \%$; the study will include a minimum of 12 specimens per cell for a total of 48 specimens. Sample size calculation was performed using IBM ${ }^{\circledR}$ SPSS $^{\circledR}$ SamplePower ${ }^{\circledR}$ Release 3.0.1

Forty-Eight human unidentified deciduous molars were used according to inclusion and exclusion criteria.

\section{Inclusion criteria:}

1) With at least intact one surface buccal or lingual.

2) Exfoliated either due to physiologic reason.

3) Indicated for extraction.

\section{Exclusion criteria:}

1) Teeth with caries on both buccal and/or lingual surfaces.

2) Fractured crown due to extraction.

3) Hypoplastic, hypocalcified.

4) Any developmental anomaly. 
The teeth were washed under running water, cleaned of residual tissue and debris, then autoclaved and stored in distilled water at $4^{\circ} \mathrm{C}$ for not more than one week $^{28,29}$. Forty-Eight teeth were divided randomly into 2 groups according to the mode of conditioning: group 1: Er,Cr:YSGG laser and group 2: conventional conditioner and each group was further divided into 2 subgroups according to the adhesive restorative material. Ethical approval was obtained from the Institutional Review Board of Misr International University (MIU) (MIU-IRB \#1718-056).

\section{Sample Preparation}

A standard class $\mathrm{V}$ cavity were prepared at the buccal or lingual surface of each tooth by using Er,Cr:YSGG laser (Waterlase iPlus, Biolase; Irvine, CA,USA) using a Waterlase iplus Gold handpiece and a MGG6 tapered sapphire tip having a fiber core diameter of $600 \mu \mathrm{m}$ till yellow dentin was seen. The laser settings were $6 \mathrm{~W}$ (peak power), frequency $15 \mathrm{~Hz}$, air pressure $60 \%$, and water pressure $80 \%$, used in noncontact mode with distance of $2 \mathrm{~mm}$ which were controlled by the aid of marked ruler, where the occlusal margin was in enamel and the gingival margin was on cementoenamel junction. The dimension of the cavity was $2 \mathrm{~mm}$ in height, width, and depth which was adjusted by using a premarked periodontal probe.

\section{Conditioning of the enamel and dentin}

In group 1 (24 teeth), conditioning with Er,Cr:YSGG laser (Waterlase iPlus, Biolase; Irvine, CA,USA) using a Waterlase iplus Gold handpiece and a MGG6 tapered sapphire tip having a fiber core diameter of $600 \mu \mathrm{m}$. The laser settings were $4.5 \mathrm{~W}$ (peak power), frequency $50 \mathrm{~Hz}$, air pressure $60 \%$, and water pressure $80 \%$, used in noncontact mode.

In group 2 (24 teeth), Dentin conditioner (GC Corporation, Tokyo, Japan) was applied on cavity surfaces, left for 20 seconds, then washed and dried slightly with a gentle stream of oil-free air to avoid desiccation.

\section{Restorative Material Application}

Group 1 (24 teeth) was subdivided into subgroup 1 containing 12 teeth, which were restored with a RMGI cement GC Fuji II LC Capsule (GC Corporation Tokyo, Japan) that was prepared according to the instructions of the manufacturer, and packed in the cavity then light curing for 20 seconds with light curing unit by light intensity of 1,500 $\mathrm{mw} / \mathrm{cm} 2$ (POLI LED Curing light, Faro, Italy) and subgroup 2 containing 12 teeth, which were restored by GI using Harvard ionoglass Cem (Harvard Dental International GmbH Margarentenstr, 2-4 15366 Hoppegarten, Germany).

Group 2 (24 teeth) was subdivided into subgroup 1 containing 12 teeth, which were restored with a RMGI cement GC Fuji II LC Capsule (GC Corporation Tokyo, Japan) that was prepared according to the instructions of the manufacturer, and packed in the cavity then light curing for 20 seconds with light curing unit by light intensity of $1,500 \mathrm{mw} /$ $\mathrm{cm} 2$ (POLI LED Curing light, Faro, Italy) and subgroup 2 containing 12 teeth, which were restored by GI using Harvard ionoglass Cem (Harvard Dental International GmbH Margarentenstr, 2-4 15366 Hoppegarten, Germany). Finishing and polishing of all the restorations were then done by finishing burs.

\section{Microleakage Test}

Restored samples were thermocycled for 700 cycles, where each cycle consists of a water bath at $5^{\circ} \mathrm{C} \pm 2^{\circ} \mathrm{C}$ and $55^{\circ} \mathrm{C}$ with a 60 -second of dwell time in each bath. By the aid of absorbent paper, the samples were superficially dried then sealed with 2 coats of nail varnish, and a window of $1 \mathrm{~mm}$ around the margins of the cavity restoration were left. To prevent penetration of the dye to the apical region, it was also sealed by epoxy glue. The samples were immersed in $2 \%$ buffered methylene blue solution for 4 hours at $\mathrm{pH} 7$, after which rinsing all samples by tap water for 5 minutes were done and dried with absorbent paper. Sectioning of each restoration was 
done by cutting it in the buccolingual direction and through the center of restoration by using low-speed and water-cooled diamond disc (KG Sorenesen). Scoring the degree of the dye penetration was done by the aid of a light stereoscope (Meiji 2000, Saitama, Japan) at X30 magnification 29) on a 4 grade scale as follows ${ }^{23}$ :

a) Score $0=$ no dye penetration

b) Score $1=$ dye penetration along the interface to one third of the cavity depth

c) Score $2=$ dye penetration along the interface to two thirds of the cavity wall depth

d) Score $3=$ dye penetration to but not along the axial wall; and e. score $4=$ dye penetration up to and along the axial wall.

\section{Statistical Analysis}

Microleakage scores showed non-normal (nonparametric) distribution. Data were presented as median and range values. Mann-Whitney $U$ test was used to compare between the two conditioning methods as well as the two materials. The significance level was set at $\mathrm{P} \leq 0.05$. Statistical analysis was performed with IBM SPSS Statistics for Windows, Version 23.0. Armonk, NY: IBM Corp.

\section{RESULTS}

\section{Comparison between conditioning methods:}

Whether with RMGI or GI; there was no statistically significant difference between median microleakage scores of the two conditioning methods $(P$-value $=0.623$, Effect size $=0.142)$ and $(P$-value $=0.623$, Effect size $=0.142)$, respectively .

\section{Comparison between materials:}

Whether with Laser or dentin conditioner; RMGI showed statistically significantly lower median microleakage scores than GI $(P$-value $=0.050$, Effect size $=0.537)$ and $(P$-value $=0.016$, Effect size $=0.800)$, respectively.

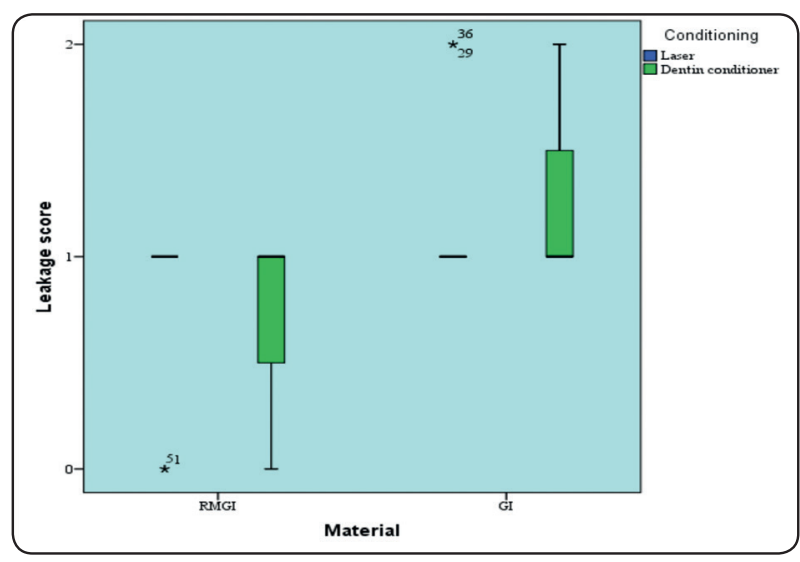

Fig. (1). Box plot representing median and range values for microleakage scores of the two cement materials with different conditioning methods (Stars represent outliers)

TABLE (1) The median, range values and results of Mann-Whitney $U$ test for comparison between microleakage scores of the two conditioning methods and the two materials

\begin{tabular}{|c|c|c|c|c|c|c|}
\hline \multirow{2}{*}{ Material } & \multicolumn{2}{|c|}{ Laser } & \multicolumn{2}{c|}{ Dentin conditioner } & \multirow{2}{*}{ P-value } & Effect size $(d)$ \\
\cline { 2 - 7 } & Median & $\begin{array}{c}\text { Range } \\
\text { (Mean rank) }\end{array}$ & Median & $\begin{array}{c}\text { Range } \\
\text { (Mean rank) }\end{array}$ & 0.623 & 0.142 \\
\hline RMGI & 1 & $0-1(10.67)$ & 1 & $0-1(9.88)$ & 0.623 & 0.142 \\
\hline GI & 1 & $1-2(14.33)$ & 1 & $1-2(15.13)$ & \\
\hline E-value & \multicolumn{2}{|c|}{$0.050^{*}$} & $0.016^{*}$ & & \\
\hline
\end{tabular}

*: Significant at $P \leq 0.05$, Mean rank is for comparison between materials 


\section{DISCUSSION}

The success of restorative treatment depends on the stability and longevity of the restoration which are affected by absence of suitable adhesion and microleakage between the tooth and the filling material, which are considered one of the main problems in adhesive restoration ${ }^{30,31}$, where several researches studied the use of enamel beveling, adhesive application, incremental cavity filling, and more recent the use of erbium laser to reduce microleakage ${ }^{32,33}$.

Several methods were used for measuring microleakage, but, the methylene blue solution used in this current study was the most common method used, due to its better penetration than other solutions because it has a smaller size than the smallest bacteria, inexpensive and easy handling ${ }^{23,34}$.

A main concern is to provide chemical bonding between the filling material and the enamel or dentin tissue to prevent penetration of bacteria from saliva into the interference between the tooth and filling materials, which causes restoration failure, discoloration of tooth, recurrent caries, pulp reaction and sensitivity after treatment ${ }^{35,36}$. For the pediatric patient, composite resins were replaced by glass ionomer as an ideal restorative material for class $\mathrm{V}$ cavities due to its, capability of forming strong bond to dental structures, biocompatibility, low shrinkage and the remineralization effect through constant fluoride release, which were the reasons for using glass ionomer in this study ${ }^{2,22}$.

Due to the multidisciplinary nature of laser, it's used in pediatric dentistry for safety and comfort of child patient, because it can lead to ablation of hard dental tissue when optimum parameters and water spray are used results in carious lesion removal and healthy tooth structures preservation with no pulp damage ${ }^{6,10,37-41}$.

Er,Cr:YSGG laser possess some advantages as, decreased noise due to lack of contact and vibration resulting in more conservation during cavity preparation and hence reduces the use of local anesthesia allowing the technique to be less traumatic for the child patient and therefore more accepted ${ }^{3,4,39,42,43}$ also the scanning electron microscope images of cavities prepared by laser showed absence of smear layer, enamel rods exposure and opened dentinal tubules, which creates a microretentive pattern that favors retention of adhesive materials, also, the enamel prisms showed a honeycomb-like appearance caused by photomechanical ablation of Er:YAG laser, in addition to ablation of the intertubular dentin rich in collagen due to the photothermal effect which results in degradation and collapsing of collagen fibers and sometimes melting collagen network ${ }^{26,27}$.

In the present study, the results revealed no significant difference in microleakage of cavities when comparing the two conditioning methods, this may be attributed to the morpholog modifications of the dental substrate created by laser which results in a morphologic pattern in the form of irregular, microretentive surface that mimics that caused by of acid etching ${ }^{2}$. On the other hand, in as study carried on by Luong and Shayegan 2108, when acid etching was compared to laser etching, the later was found to be less technique sensitive and leads to higher control over the area needed to be etched precisely ${ }^{6}$.

In the current study RMGI showed statistically significantly lower median microleakage scores than GI, which was in accordance to the results of a study done by Luong and Shayegan 2108, and a study done by Pontes et al. 2014, have shown that resin-modified GI showed less leakage compared with conventional $\mathrm{GI}^{6,44}$.

In a study conducted by Rossi et al. 2008, they concluded that the RMGIC Vitremer showed the statistically significant lowest degree of microleakage, compared with the Ketac Molar conventional CGIC, and was highly evident in the lased cavities ${ }^{2}$, this may be attributed to that a larger part of CGIC adheres chemically to the tooth structure by ion exchanges between the carboxylate ions of the material and the calcium and phosphate 
ions of the dental tissues in addition to little micromisalignment adhesion, while the RMGIC adhesion to dental tissues by misalignment of its resinous part in addition to chemical adhesion from its polyacrylic acid component and also, through the hybrid layer formation by the hydrophilic HEMA ${ }^{2,15}$. Furthermore the modifications created by the laser which results in a morphologic pattern characterized by irregular and microretentive surface which is similar to that done by acid etching together with the additional morphologic alterations caused by laser which are absence of smear layer and opening of dentinal tubules enhances the micromisalignment and therefore the adhesion between the restorative material and the tooth surface ${ }^{2}$.

On the contrary to the present study Chinelatti et al. 2006, demonstrated that the Er:YAG laser negatively affect the marginal seal of cavities in permanent teeth restored with RMGIC and this was attributed to the raised density of energy which may damage the morphologic structure, resulting in alteration of the collagen fibrils and negatively affect the adhesion of restorative material to the cavity $^{15}$. the same results have been discovered by Corona et al. 2001, where they stated that laser had a negative influence on the marginal seal and leads to increase in the degree of microleakage of cavities restored by $\mathrm{RMGIC}^{20}$.

\section{CONCLUSION}

Based on the results of the current study, it can be concluded that:

1. Er,Cr:YSGG laser have adverse effect on the microleakge of cavities restored by RMGI and GI.

2. RMGI is clinically preferred than GI as it showed statistically significantly lower median microleakage scores.

3. Application of the Er:YAG laser, beneath the RMGIs amd GI may be an alternative to acid etching

\section{REFERENCES}

1. Muhammed G. \& Dayem R. Evaluation of the microleakage of different class $\mathrm{V}$ cavities prepared by using Er:YAG laser, ultrasonic device, and conventional rotary instruments with two dentin bonding systems (an in vitro study). Lasers Med Sci 2015; 30:969-975.

2. Rossi R R, Aranha A C, Eduardo C de P, Ferreira L S, Navarro R S., Zezell D M. Microleakage of Glass Ionomer Restoration in Cavities Prepared by Er,Cr:YSGG Laser Irradiation in Primary Teeth. J Dent Child 2008; 75:151-157.

3. Kotlow LA. Lasers in pediatric dentistry. Dent Clin North Am 2004; 48:889-922.

4. Celiberti P, Francescut P, Lussi A. Performance of four dentine excavation methods in deciduous teeth. Caries Res 2006; 40:117-123.

5. Kotlow LA. Lasers in pediatric dentistry. Dent Clin North Am 2004; 48:889-922.

6. Luong E, Shayegan A. Assessment of microleakage of class $\mathrm{V}$ restored by resin composite and resin-modified glass ionomer and pit and fissure resin-based sealants following Er:YAG laser conditioning and acid etching: in vitro study. Clin Cosmetic and Investig. Dent. 2018; 10:83-92.

7. Kato J, Moriya K, Jayawardena JA, Wijeyeweera RL. Clinical application of Er:YAG laser for cavity preparation in children. J Clin Laser Med Surg 2003;21: 151-1555.

8. Baghalian A, Nakhjavani YB, Hooshmand T, Motahhary P, Bahramian H. Microleakage of Er:YAG laser and dental bur prepared cavities in primary teeth restored with different adhesive restorative materials. Lasers Med Sci. 2013; 28:1453-1460.

9. Visuri SR, Gilbert JL, Wright DD, Wigdor HA, Walsh Jr JT. Shear strength of composite bonded to Er:YAG laserprepared dentin. J Dent Res 1996; 75:599-605.

10. Kalyoncu IO, Eren-Giray F, Huroglu N, Egil E, Tanboga I. Microleakage of Different Adhesive Systems in Primary Molars Prepared by Er: YAG Laser or bur. Niger J Clin Pract 2018; 21:242-247.

11. Sertac Peker, Figen Eren Giray, Basak Durmus, Nural Bekiroglu, Betül Kargül \& Mutlu Özcan. Microleakage in class $\mathrm{V}$ cavities prepared using conventional method versus Er:YAG laser restored with glass ionomer cement or resin composite, J Adhesion Sci and Tech. 2017; 31(5):509-519. 
12. Ceballos L, Osorio R, Toledano M, Marshall GW. Microleakage of composite restorations after acid or Er- YAG laser cavity treatments. Dent Mater 2001;17: 340-346.

13. Groth EB, Mercer CE, Anderson P. Microtomographic analysis of subsurface enamel and dentine following Er: YAG laser and acid etching. Eur J Prosthodont Restor Dent 2001; 9:73-79.

14. Matsumoto K, Hossain M, Kawano H, Kimura Y. Clinical assessment of Er,Cr:YSGG laser application for cavity preparation. J Clin Laser Med Surg 2002; 20:17-21.

15. Chinelatti MA, Ramos RP, Chimello DT, Corona SA, Pecora JD, Dibb RG. Influence of Er:YAG laser on cavity preparation and surface treatment in microleakage of composite resin restorations. Photomed Laser Surg 2006; 24:214-218.

16. Featherstone JD. Caries detection and prevention with laser energy. Dent Clin North Am 2000; 44:955-969.

17. Moritz A, Schoop U, Goharkhay K, Szakacs S, Sperr W, Schweidler E, et al. Procedures for enamel and dentin conditioning: A comparison of conventional and innovative methods. J Esthet Dent 1998; 10:84-93.

18. Jean A, Armengol V, Assoumou M, Hamel H. Microleakage along composite restoration following Er: YAG laser irradiation versus acid-etched. J Dent Res 1998; 77:937.

19. Toledano M, Osorio E, Osorio R, Garcia-Godoy F. Microleakage of Class V resin-modified glass ionomer and compomer restorations J Prosthet Dent 1999; 75:871-878.

20. Corona SAM, Borsatto MC, Palma-Dibb RB, Ramos RP, Brugnera Jr A, Pécora JD. Microleakage of Class V resin composite restorations after bur, air abrasion, or Er:YAG laser preparation. Oper Dent 2001;26: 491-497.

21. Kohara EK, Hossain M, Kimura Y, Matsumoto K, Inoue M, Sasa R. Morphological and microleakage studies of the cavities prepared by Er:YAG laser irradiation in primary teeth. J Clin Laser Med Surg 2002; 20:141-147.

22. Aranha AC, Turbino ML, Powell GL, Eduardo CP. Assessing microleakage of Class $\mathrm{V}$ resin composite restorations after Er:YAG laser and bur preparation. Lasers Surg Med 2005; 37:172-177.

23. Ghandehari M, Mighani G, Shahabi S, Chiniforush N, Shirmohammadi Z. Comparison of Microleakage of Glass Ionomer Restoration in Primary Teeth Prepared by Er: YAG Laser and the Conventional Method. J Dent, Tehran University of Medical Sciences 2012; 9(3):215-220.
24. Parkins F. Laser in pediatric and adolescent dentistry. Dent Clin North Am. 2000 ;44(4):821-30.

25. Kornblit R, Bossù M, Mari D, Rocca JP, Polimeni A. Enamel and dentine of deciduous teeth Er:YAG laser prepared. A SEM study. Eur J Paediatr Dent. 2009 ;10(2):75-82.

26. Delme KI, De Moor RJ. Scanning electron microscopic evaluation of enamel and dentin surfaces after Er:YAG laser preparation and laser conditioning. Photomed Laser Surg. 2007 ;25(5):393-401.

27. Schien MT, Bocangel JS, Nogueira GE, Schien PA. SEM evaluation of the interaction pattern between dentin and resin after cavity preparation using Er:YAG laser. J Dent. 2003 ;31(2):127-135.

28. Scatena C, Torres CP, Gomes-Silva JM, Contente MM, Pécora JD, Palma-Dibb RG, et al. Shear strength of the bond to primary dentin: Influence of Er: YAG laser irradiation distance. Lasers Med Sci. 2011; 26(3):293-297.

29. Bahrololoomi Z, Ghafourifard R. Shear Bond Strength of Primary Teeth Dentin Irradiated with Different Erbiumdoped Yttrium Aluminium Garnet Laser Energies and Scanning Electron Microscope Study of Dentin Morphology. J Inter Oral Health 2016; 8(10):943-947.

30. Küçükeşmena C, Sönmez H. Microleakage of Class-V composite restorations with different bonding systems on fluorosed teeth. Eur J Dent. 2008 ;2(1):4858.

31. Ozel E, Korkmaz Y, Attar N, Bicer CO, Firatli E. Leakage pathway of different nanorestorative materials in class $\mathrm{V}$ cavities prepared by Er:YAG laser and bur preparation. Photomed Laser Surg. 2009 ;27(5):783-789.

32. Armengol V, Jean A, Enkel B, Assoumou M, Hamel H. Microleakage of class $\mathrm{V}$ composite restorations following Er:YAG and Nd:YAP laser irradiation compared to acidetch: an in vitro study. Lasers Med Sci. 2002, 17(2): 93-100.

33. Yamada Y, Hossain M, Nakamura Y, Murakami Y, Matsumoto K. Microleakage of composite resin restoration in cavities prepared by Er:YAG laser irradiation in primary teeth. Eur J Paediatr Dent. 2002 ;3(1):39-45.

34. Rasmy AHM, Harhash TA, Ghali RMS, El Maghraby EMF, El Rouby DH. Comparative study between laser and conventional techniques for class $\mathrm{V}$ cavity preparation in gammairradiated teeth (in vitro study). J Appl Oral Sci. 2017;25(6):657-65. 
35. Ceballos L, Toledano M, Osorio R, García-Godoy F, Flaitz C, Hicks J. ER-YAG laser pretreatment effect on in vitro secondary caries formation around composite restorations. Am J Dent. 2001 ;14(1):46-9.

36. Browning WD, Dennison JB. A survey of failure modes in composite resin restorations. Oper Dent. 1996;21(4): 160-6.

37. Yamada Y, Hossain M, Nakamura Y, Suzuki N, Matsumoto K. Removal of carious dentin by mechanical, chemomechanical, and Er:YAG laser in deciduous teeth. J Clin Laser Med Surg 2001; 1:109-114.

38. Hossain M, Nakamura Y, Yamada Y, Murakami Y, Matsumoto K. Microleakage of composite resin restoration in cavities prepared by Er,Cr:YSGG laser irradiation and etched bur cavities in primary teeth. J Clin Pediatr Dent 2002; 26:263-268.

39. Hossain M, Nakamura Y, Tamaki Y, Yamada Y, Murakami Y, Matsumoto K. Atomic analysis and Knoop hardness measurement of the cavity floor prepared by Er,Cr:YSGG laser irradiation in vitro. J Oral Rehabil 2003; 30:515-521.
40. Navarro RS, Gontijo I, Raggio D, Imparato JCP, GuedesPinto AC, Eduardo CP. Conservative and minimal intervention in caries with Er:YAG and Er,Cr:YSGG lasers in pediatric dentistry. Braz Dent J 2004; 15:78.

41. Sung EC, Chenard T, Caputo AA, Amodeo M, Chung EM, Rizoiu IM. Composite resin bond strength to primary dentin prepared with Er,Cr:YSSG laser. J Clin Pediatr Dent 2005; 30:45-49.

42. Harashima T, Kinoshita J, Kimura Y, Brugnera A, Zanin F, Pecora JD, Matsumoto K. Morphological comparative study on ablation of dental hard tissues at cavity preparation by Er:YAG and Er,Cr:YSGG lasers. Photomed Laser Surg 2005; 23:52-55.

43. Hadley J, Young DA, Eversole LR, Gornben JAA. Laserpowered hydrokinetic system for caries removal and cavity preparation. J Am Dent Assoc 2000; 131:777-785.

44. Pontes DG, Guedes-Neto MV, Cabral MF, Cohen-Carneiro F. Microleakage evaluation of class $\mathrm{V}$ restorations with conventional and resin-modified glass ionomer cements. Oral Health Dent Manag. 2014; 13:642-646. 